night call off Montauk which had caused him to lay awake wondering how she could possibly have gotten so far inshore in the course of the short run from Nantucket. (I should have mentioned above that the offshore light-vessels, such as Nantucket, had diesel power for use in going to and from station. I don't believe they could do much better than six or eight knots however and at a distance appeared to be stationary.)

\title{
Marine and Air Traffic Control
}

\section{J. D. Proctor}

MARINE and air navigation can still learn from each other. Mariners are following aviation in adopting some routing and control but aviation could follow mariners in their refusal to accept routing and control unless it is cost effective. However it may be easier in the marine case to measure the cost and probability of a collision than it is in the aerial case. But many states have established mandatory airways and routes; originally their navigational aids were very useful and in the event of forced landing the search and rescue people knew where to look. But many airliners now have self-contained navaids like the inertial navigation system (INS) or doppler so that they can navigate off airways, and also forced landings are rare. In the history of air traffic control at first it applied only around airports; when it spread to routes many aircraft were quite happy to fly off airways. But now airways have proliferated and have become customary and respectable to airline pilots so that few complain when some states force aircraft to follow lengthy and costly routes. The only virtue of airways is their freedom, theoretically, from uncontrolled traffic and from military dangers. If A.T.C. were confined to those situations where the risk of collision without A.T.C. would be worse than, say $I$ in $10,000,000$, flying would be a little more expeditious, but everyone feels secure within the system and insecure, guilty and uncomfortable outside it, so A.T.C. is used universally by airliners. Of course traffic density often necessitates routing under present systems of air traffic control. For example over perhaps half of the United States at jet cruising level any route may be followed with A.T.C. permission with a radar vectoring service around any traffic at one's own level and with advice from A.T.C. of the flight levels of other aircraft which may be near enough to be seen. Over the other half the permitted routes are limited to specified routes unless traffic is light.

The navigation of airliners along airways and routes is nothing like as precise as the navigation of a train along its track. Airliners on an airway are dispersed over at least a few miles laterally and a few hundred feet vertically. So mistakes by controllers and pilots which happen in every flight information region (FIR) most days are unimportant, unlike mistakes on railways. In the en route phase in the air a mistake lowers the level of safety only a little, from perhaps $10^{-7}$ to $10^{-5}$. In many cases natural dispersion provides more safety than A.T.C. does but sacred A.T.C. which is generally essential and excellent is ubiquitous. In many areas mandatory routes force aircraft to congregate and so increase the traffic density so much that A.T.C. becomes necessary. Nearer the runway 
natural dispersion is less and mistakes, which are fewer, are more serious, and A.T.C. is more important. At sea there are only two dimensions of space but, unlike in the air, stopping is possible and encounters are nearly always dealt with satisfactorily by use of ships' radar and direct vision. It seems only in the highest traffic density are routing and control necessary.

For the air rules for visual avoidance of collision are irrelevant and are forgotten soon after the examinations are passed. For the sea Calvert and Hollingdale proposed a mathematical solution to the problem. It failed perhaps because :

(a) without communication the case of the small negative miss, which might lead to mutually cancelling manœuvres, was insoluble,

(b) it ignored the delaying effect of turning away,

(c) it ignored the delaying effect of reducing speed, and

(d) it showed how to prevent collision but sometimes at the expense of getting to the destination; on resuming course the conflict might recur.

The Rules are being altered so as to permit dual manœuvres in all encounters without requiring them both to be of positive sign and without requiring v.h.f. communication which seems to provide the best hope of preventing mutually cancelling mancuvres. The Rules do however discourage the confusing succession of small alterations. To facilitate v.h.f. communication between ships of different tongues there is already an international alphanumeric code: what is needed now is a standard format for anti-collision messages.

Communication may require the specification of standard position lines which may be lines of bearing from prominent points or meridians or parallels of latitude. Messages should perhaps take this form:

(a) call sign,

(b) magnetic bearing and distance of relevant radar echoes or ships in sight,

(c) track and groundspeed, position and time,

(d) type of ship,

(e) whether radar equipped,

$(f)$ destination,

(g) manœuvring intention.

Element $(b)$ is placed early so that a ship hearing a message may tell early whether the speaker is a ship relevant to her and so may decide whether or not to take down the rest of the message.

The inability of the operator to measure visibility does not prevent the authorities from framing rules of aviation in numerical terms of in-flight visibility. Should not the same apply to the sea?

R. B. Adams (this Journal 25,467) distrusts the idea of ships being talked in and invokes the third dimension as permitting the aviator to 'overfly' by which I take it he means 'abandon the approach', whereas the mariner cannot. But, even without the third dimension, surely ships have the same ability to abandon an approach, by turning, stopping or reversing, up to the decision point beyond which they are committed to berth?

Nowadays Ground Controlled Approach (GCA) is seldom used by airliners; on an approach the pilot is dependent on ground personnel only for assurance (a) that the approach and runway are clear and $(b)$ that the Instrument Landing System (ILS) is operating properly and (c) for information on landing conditions. 
Down to the decision point the aircraft is flown down the ILS beam manually or automatically. At or before the decision point the pilot decides whether he can see the ground well enough to land: if not he goes around and climbs away. Is not the marine situation similar?

Now that Grimes (this Journal 25, 496) has shown that British tankers have the most accidents in NW. Europe, I hope figures of exposure to risks will be produced so that the accident rate can be seen in a proper perspective. 